\title{
CHARACTERIZATION OF DELAMINATIONS AND TRANSVERSE MATRIX CRACKS IN COMPOSITE LAMINATES USING MULTIPLE-ANGLE ULTRASONIC INSPECTION
}

\author{
Patrick H. Johnston ${ }^{1}$, Chelsea D. Appleget ${ }^{2,4}$, and Michael T. Odarczenko, \\ ${ }^{1}$ NASA Langley Research Center, Hampton, VA 23681 \\ ${ }^{2}$ Auburn University, Auburn, AL 36849 \\ ${ }^{3}$ University of Illinois, Champaigne, IL 61820 \\ ${ }^{4}$ Langley Aerospace Research Summer Scholars (LARSS) Program
}

\begin{abstract}
Delaminations and transverse matrix cracks often appear concurrently in composite laminates. Normal-incidence ultrasound is excellent at detecting delaminations, but is not optimum for matrix cracks. Non-normal incidence, or polar backscattering, has been shown to optimally detect matrix cracks oriented perpendicular to the ultrasonic plane of incidence. In this work, a series of six composite laminates containing slots were loaded in tension to achieve various levels of delamination and ply cracking. Ultrasonic backscattering was measured over a range of incident polar and azimuthal angles, in order to characterize the relative degree of damage of the two types. Sweptpolar-angle measurements were taken with a curved phased array, as a step toward an array-based approach to simultaneous measurement of combined flaws.
\end{abstract}

Keywords: Ultrasonic, Polar Backscatter, Composites, Delamination, Crack, Array

PACS: $43.35 . Z \mathrm{c}$

\section{INTRODUCTION}

Structures and materials researchers at NASA Langley Research Center (LaRC) have been developing computational models of damage progression in composite laminates under load [1]. The Nondestructive Evaluation Sciences Branch (NESB) was engaged to experimentally verify these computational models. Because delaminations and transverse matrix cracks were expected to occur in specimens concurrently, a full characterization would have to measure both types of damage. The most accessible approach to apply on a load frame was normal-incidence pulse-echo ultrasound, which was an optimum ultrasonic approach for delaminations, but was not optimum for transverse matrix cracks [2,3].

Many researchers, beginning with Bar-Cohen and Crane in 1982, have demonstrated that an oblique incidence pulse-echo approach (also known as polar backscatter) can selectively measure transverse matrix cracks [4-6]. Delaminations, which are predominantly in-plane, present a maximum backscattering cross-section to normallyincident waves (Fig. 1A). Transverse matrix cracks tend toward the vertical orientation, and 
thus present a maximum cross-section for waves with in-plane propagation oriented normal to the crack length (Fig. 1B).

In this paper, we present results demonstrating the benefits of measuring polar backscatter over a range of azimuthal angles. Measurements made with a standard immersion focused transducer will be presented, as well as measurements made with a curved linear array, capable of electronically scanning over a range of polar angles.

\section{POLAR BACKSCATTER GEOMETRY}

The geometry for polar backscattering measurements is illustrated in Fig. 1C. A polar coordinate system is imposed, with the $\mathrm{X}-\mathrm{Y}$ plane parallel to the surface of the composite laminate and the $\mathrm{X}$ axis parallel to the $0^{\circ}$ direction. The $\mathrm{Z}$ axis extends perpendicularly to the surface of the laminate. The angle from the $\mathrm{Z}$ axis to the direction of the incident beam is the polar angle, $\theta$. The rotational angle relative to the $\mathrm{X}$ axis is the azimuthal angle, $\phi$. For reference, the fiber orientations of a quasi-isotropic laminate are shown in Fig. 1D, with $0^{\circ}$ fibers parallel to the $\mathrm{X}$ axis, and $90^{\circ}$ fibers parallel to the $\mathrm{Y}$ axis.

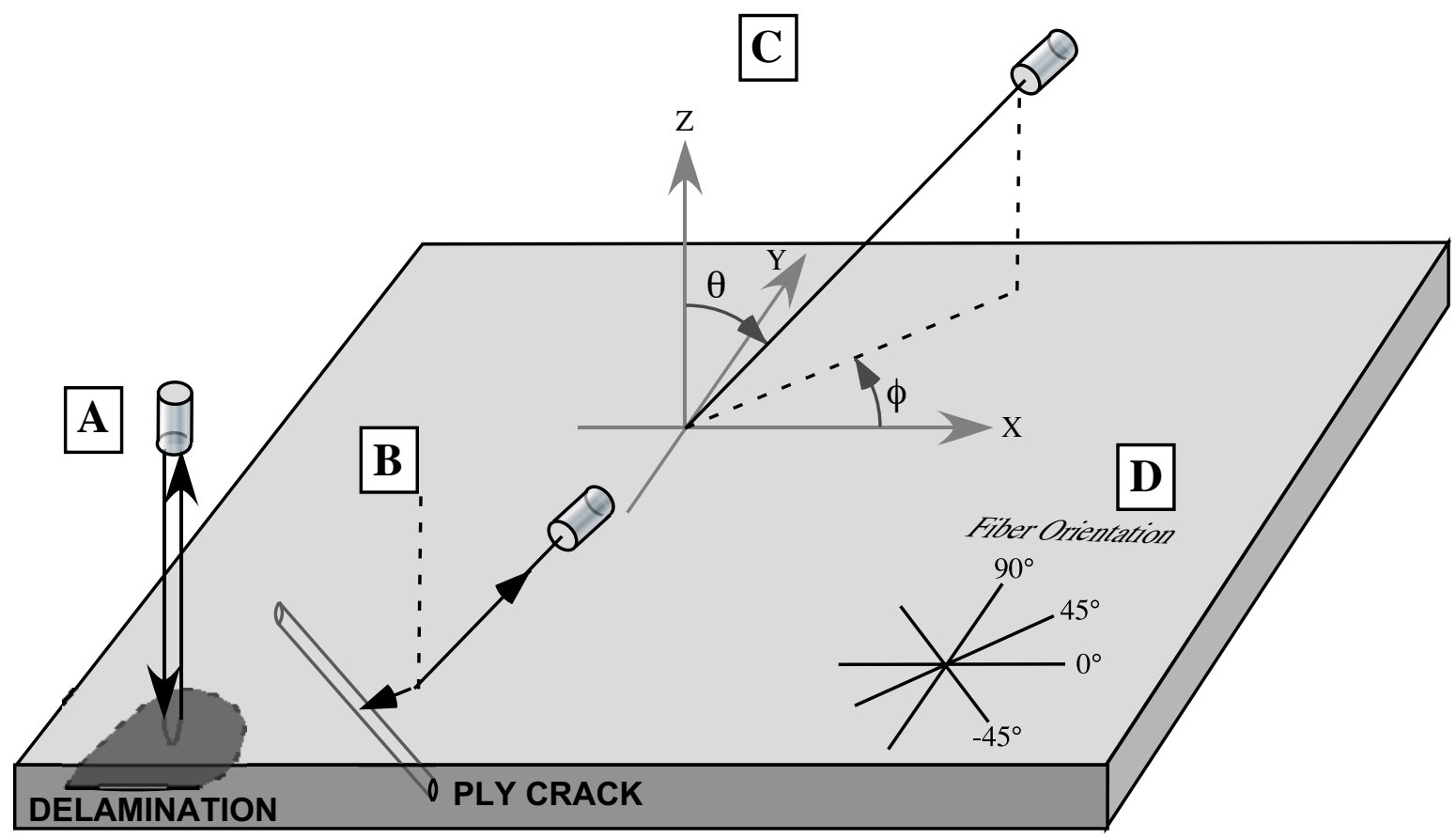

FIGURE 1. A schematic of the polar backscatter measurement configuration.

\section{SPECIMENS}

Six 8-ply T800/3900-2 quasi-isotropic laminates from a previous study [7] were measured using the polar backscatter technique. Several different ply layups were represented, as shown in Table 1. Each panel had a 3-inch x 6-inch test area, with a 0.75inch-long slot (with width shown in Table 1) at its center as a stress concentrator. Each specimen had been loaded monotonically in tension at a rate of $0.005 \mathrm{in} / \mathrm{min}$ up to some target load. Differences in ply layup and net load resulted in a variable degree of delamination and transverse matrix cracking. The front surface of all specimens had speckled paint which was applied to enable digital image correlation during the load test, but did not appear to influence the ultrasonic measurements. 
TABLE 1. Description of the six composite panels measured for this report.

\begin{tabular}{|c|c|c|c|c|c|}
\hline Number & Name & Ply Layup & Net Load & Slot Width & Comments \\
\hline 1 & LS\#7 SP-2 & {$[90 /-45 / 0 / 45 / 0]_{\mathrm{s}}$} & $16,732 \mathrm{lbs}$ & $0.092 \mathrm{in}$ & Slot cut with drill \\
\hline 2 & LS1G-2 & {$[-45 / 0 / 45 / 0 / 90]_{\mathrm{s}}$} & $15,034 \mathrm{lbs}$ & $0.030 \mathrm{in}$ & Slot cut with laser \\
\hline 3 & LS1F-2 & {$[-45 / 0 / 45 / 0 / 90]_{\mathrm{s}}$} & $15,588 \mathrm{lbs}$ & $0.030 \mathrm{in}$ & Slot cut with laser \\
\hline 4 & LS\#8 SP-2 & {$[90 /-45 / 0 / 0 / 45]_{\mathrm{s}}$} & $19,703 \mathrm{lbs}$ & $0.092 \mathrm{in}$ & Slot cut with drill \\
\hline 5 & LS\#7 SP-3 & {$[90 /-45 / 0 / 45 / 0]_{\mathrm{s}}$} & $14,500 \mathrm{lbs}$ & $0.092 \mathrm{in}$ & Slot cut with drill \\
\hline 6 & LS\#6 SP-2 & {$[0 /-45 / 0 / 45 / 90]_{\mathrm{s}}$} & $15,500 \mathrm{lbs}$ & $0.092 \mathrm{in}$ & Slot cut with drill \\
\hline
\end{tabular}

\section{POLAR BACKSCATTER WITH CONVENTIONAL IMMERSION TRANSDUCER}

\section{Measurement Approach}

The specimens were scanned on a flat glass plate parallel to the X-Y plane in an immersion scan tank, with the sides of the specimen parallel to the $\mathrm{X}$ and $\mathrm{Y}$ axes. An immersion transducer ( $10 \mathrm{MHz}, 0.5$ inch diameter, 4 inch focus) was mounted on a Z-axis search tube having a manual gimbal to provide variable polar angle and a motorized rotary stage to allow control of azimuthal angle. To enable registration of sequential scans, a $0.25-$ inch diameter stainless steel ball was placed at a known, fixed offset from the specimen as a reference point. After each angular adjustment, the transducer was translated to place the ball at its focus to reestablish registration of the beam with the scan area. Broadband backscatter data were acquired using a $200 \mathrm{MHz}$ bandwidth pulser/receiver and a 12-bit digitizer board at $100 \mathrm{MHz}$ sampling rate.

Specimen 1 was initially scanned by itself, after which specimens 2-6 were placed adjacent to one another and scanned together. All the $\mathrm{C}$-scans presented here had spatial sampling interval of 0.02 inches.

\section{Normal-Incidence Results}

Figure 2 shows C-scan results from a normal-incidence scan of the six specimens. The data was gated to exclude the front- and back-wall reflections, to highlight any echoes resulting from internal delaminations. The root mean square (RMS) of the RF waveform is plotted. Delamination signals are prominently observed in specimens 1-4, associated with the ends of the slot. In addition, specimens 2, 3 and 6 contain echoes from delaminations along the edges of the panels, while the other three do not. It may be noted that the three panels with edge delaminations all have doubled $90^{\circ}$ plies at mid-plane $\left([* / * / * / * / 90]_{\mathrm{s}}\right)$, while the others all have their $90^{\circ}$ fibers in the outermost plies $\left([90 / * / * / * / *]_{\mathrm{s}}\right)$.

\section{Polar Backscatter Results}

Figure 3 shows the RMS C-scans of polar backscatter from the six specimens at a $20^{\circ}$ polar angle, and four different azimuthal angles: $90^{\circ}, 45^{\circ}, 0^{\circ}$ and $-45^{\circ}$. (The polar angle of $20^{\circ}$ was chosen as a first approximation; it was not based on any optimization). The entire measured polar backscatter signal is included in the RMS calculation. The angles of incidence are stated as ordered pairs $(\theta, \phi)$, e.g. $(20,90)$.

There are two main points to make regarding these results. The first is the huge contrast between the polar backscatter C-scans (Fig. 3) and the corresponding normalincidence C-scans (Fig. 2). The amount of information about the state of the composite laminates contained in Fig. 3, which is not observed in Fig. 2, is remarkable. In particular, 


\section{NORMAL INCIDENCE}

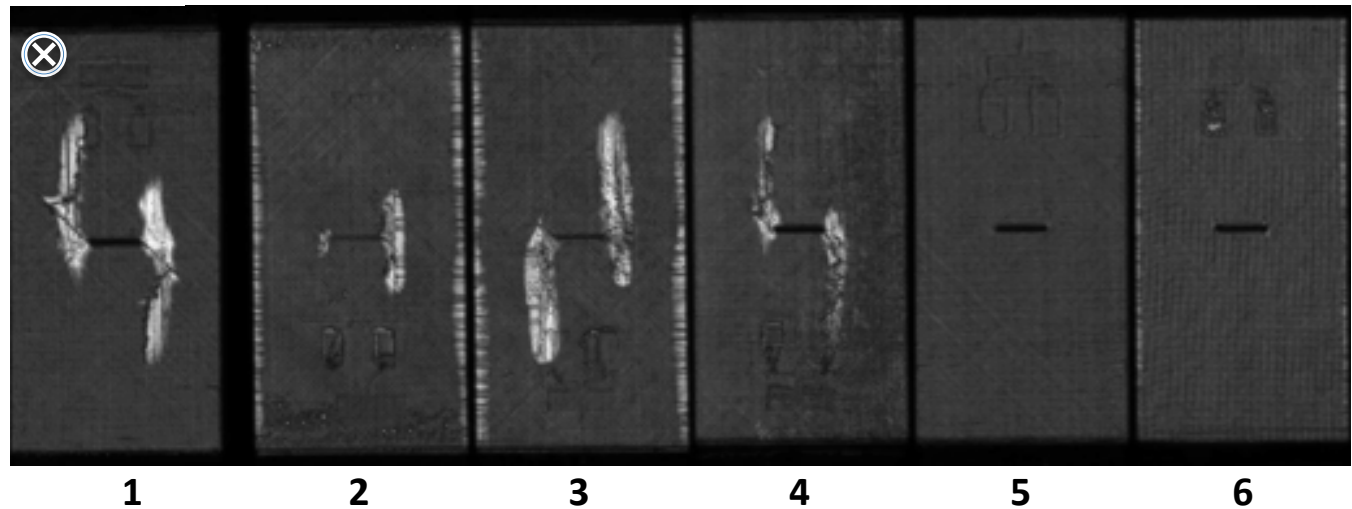

FIGURE 2. Normal-incidence backscatter measurements (RMS value of RF within gate on interior region, excluding front and back walls) for all 6 panels.

the normal-incidence results show no indication of the $45^{\circ}$ cracks observed by the $(20,-45)$ interrogation, or the widespread $-45^{\circ}$-oriented cracks highlighted by the polar backscatter at $(20,45)$. It should be noted that all of the $(20, \phi)$ data for specimens $2-6$ are part of the same data set, taken in a single scan, so there is a constant gain across these specimens and the observed amplitude differences are real.

The second point is the existence of correlated damage states with the ply layup order. For example, a similarly-patterned distribution of $-45^{\circ}$ cracking is observed at $(20,45)$ for specimens 1,4 and 5 , which have a ply layup of $[90 /-45 / 0 / * / *]_{s}$. This is very different from the distribution observed in the other three specimens, having ply layups $[-45 / 0 / 45 / * / *]_{\mathrm{s}}$ or $[0 /-45 / 0 / * / *]_{s}$. There are many of these sorts of correlations, but detailed discussion of these falls outside the scope of this paper.

\section{POLAR BACKSCATTER WITH CURVED LINEAR ARRAY}

\section{Measurement Approach}

In order to investigate the polar angle dependence of backscatter for these specimens, a curved linear array was used, as depicted in Fig. 4. The array used (Olympus 5CC25-R4) was $5 \mathrm{MHz}, 32$ elements, $1.3 \mathrm{~mm}$ pitch, $6 \mathrm{~mm}$ height and $25 \mathrm{~mm}$ radius of curvature. With the center of curvature located at the surface of the specimen, an aperture of 4 contiguous elements was electronically scanned by 1 element steps to measure backscatter from a point on the specimen over a $-39^{\circ}$ to $39^{\circ}$ range of polar angles. The grayscale B-scan type image in Fig. 4 illustrates the signal amplitude with increasing time (distance from array) from top to bottom and the scanned polar angle in the horizontal. For angles surrounding $0^{\circ}$ (normal-incidence), the usual front and back wall echoes are observed, as well as the reflections from the underlying glass plate. On either side, at polar angles in the \pm 20 's of degrees, appear the polar backscatter signals. (For illustration, a particularly symmetric example was chosen.) The observed center of the polar backscatter signal was approximately $\pm 27^{\circ}$. This is consistent with other published results for carbonepoxy composites, where optimum polar angles ranging from $22^{\circ}$ to $30^{\circ}$ were reported.

To further illustrate the polar angle dependency, data were acquired as the array was scanned along a line in the $\mathrm{X}$ direction, as depicted in Fig. 5. The polar backscatter signal is observed to be mostly non-symmetric, and to vary substantially along the linear scan, but to remain within a range of polar angles, with center approximately $\pm 27^{\circ}$. 


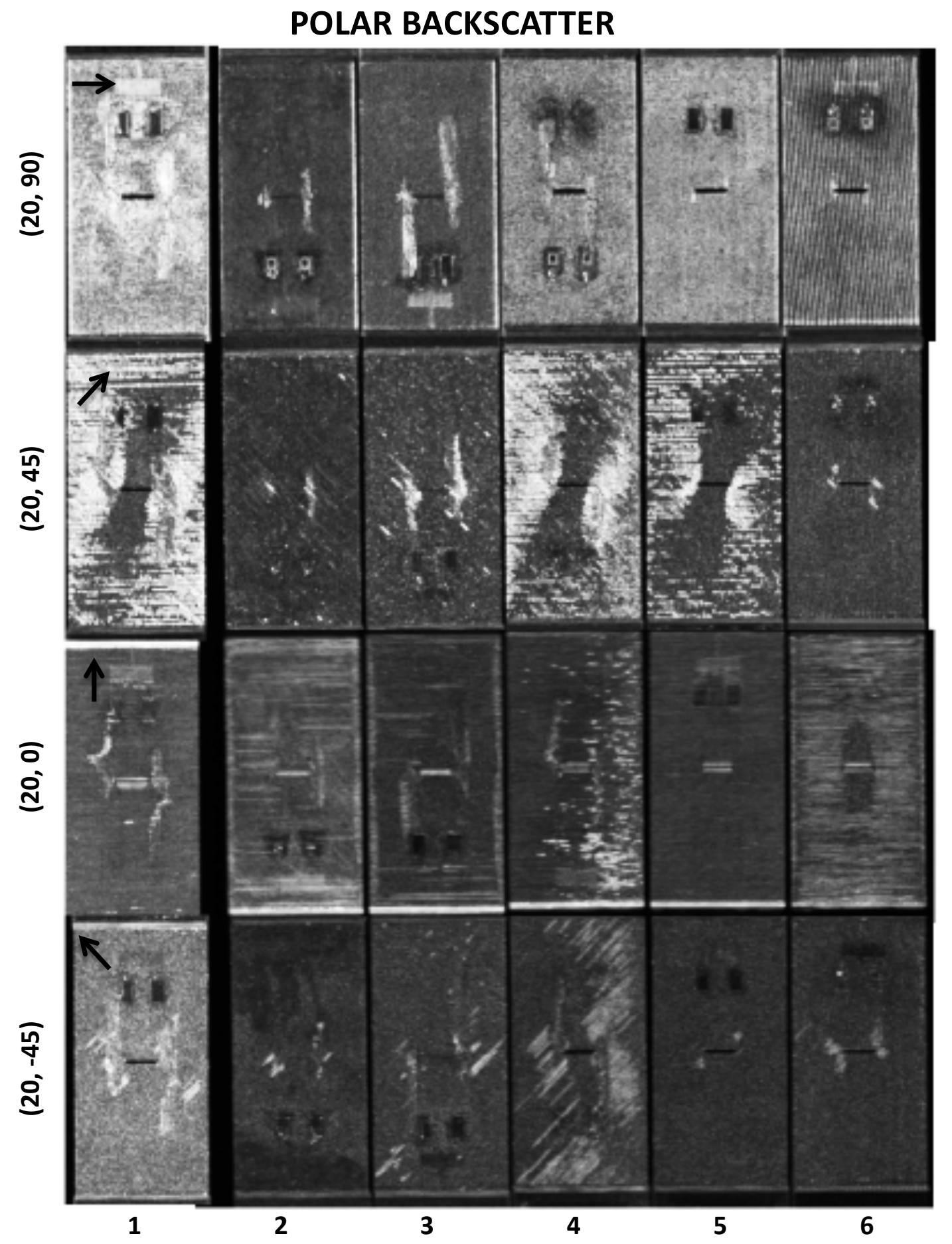

FIGURE 3. Polar backscatter measurements (RMS values of RF with wide gate) for all 6 panels, at polar angle of $20^{\circ}$ and azimuthal angles of $90^{\circ}, 45^{\circ}, 0^{\circ}$ and $-45^{\circ}$. Arrows indicate the azimuthal angle of incidence.

With a fixed aperture at polar angle $27^{\circ}$, and azimuthal angle $45^{\circ}$, the array was then scanned in $\mathrm{X}-\mathrm{Y}$ to provide a $\mathrm{C}$-scan of polar backscatter. Fig. 6 shows this data, compared with an optical photograph of the specimen. The polar backscatter strongly indicates the surface breaking cracks oriented at $-45^{\circ}$, with lower amplitude signals from the other visible fractures. This $(27,45)$ may be compared with the $(20,45)$ data for specimen 1 in Fig. 3 (note the relative rotation). The results are qualitatively very different, 


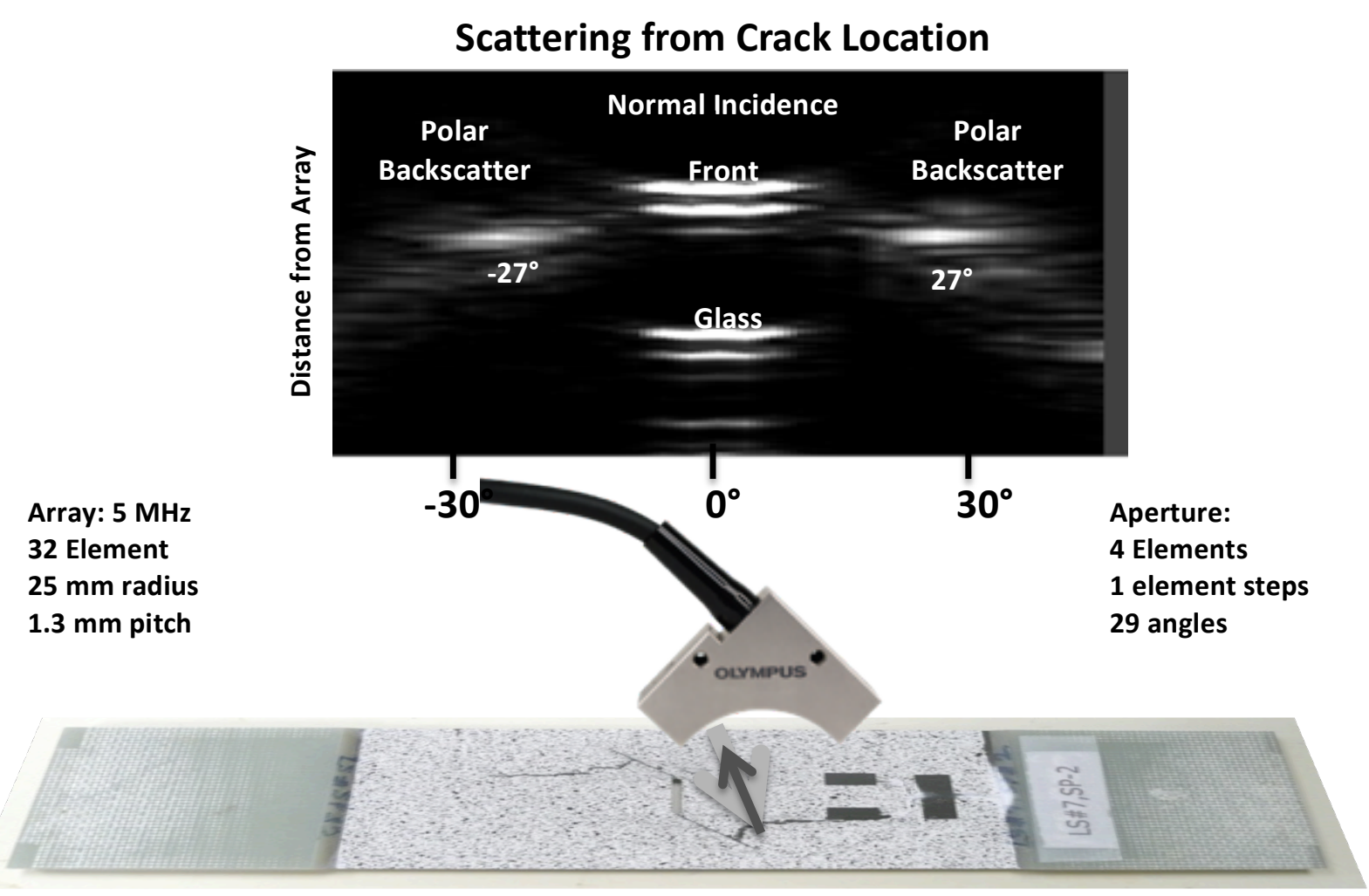

FIGURE 4. A curved linear phased array probe provided a means to scan polar backscatter over a $\pm 39^{\circ}$ range. At $0^{\circ}$ incidence, the usual echoes from front and back surfaces are observed, as are the echoes from the underlying glass plate. On either side, centered at approximately $\pm 27^{\circ}$, are the polar backscatter signals.

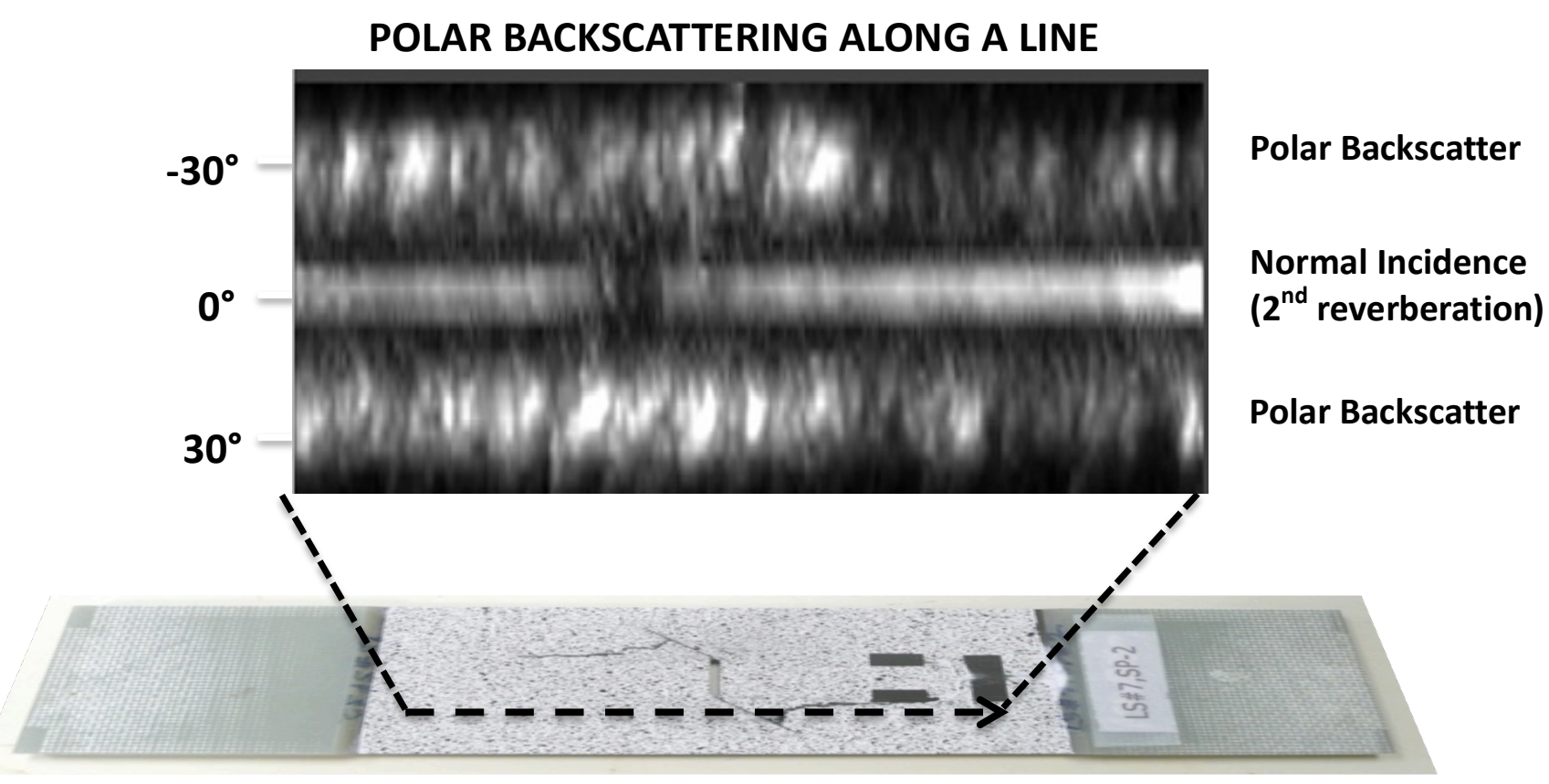

FIGURE 5. Polar backscatter (P-P amplitude) for $\pm 39^{\circ}$ polar angle versus distance along a line. Polar backscatter magnitude varies significantly, but remains within a band of polar angles centered near $\pm 27^{\circ}$. 

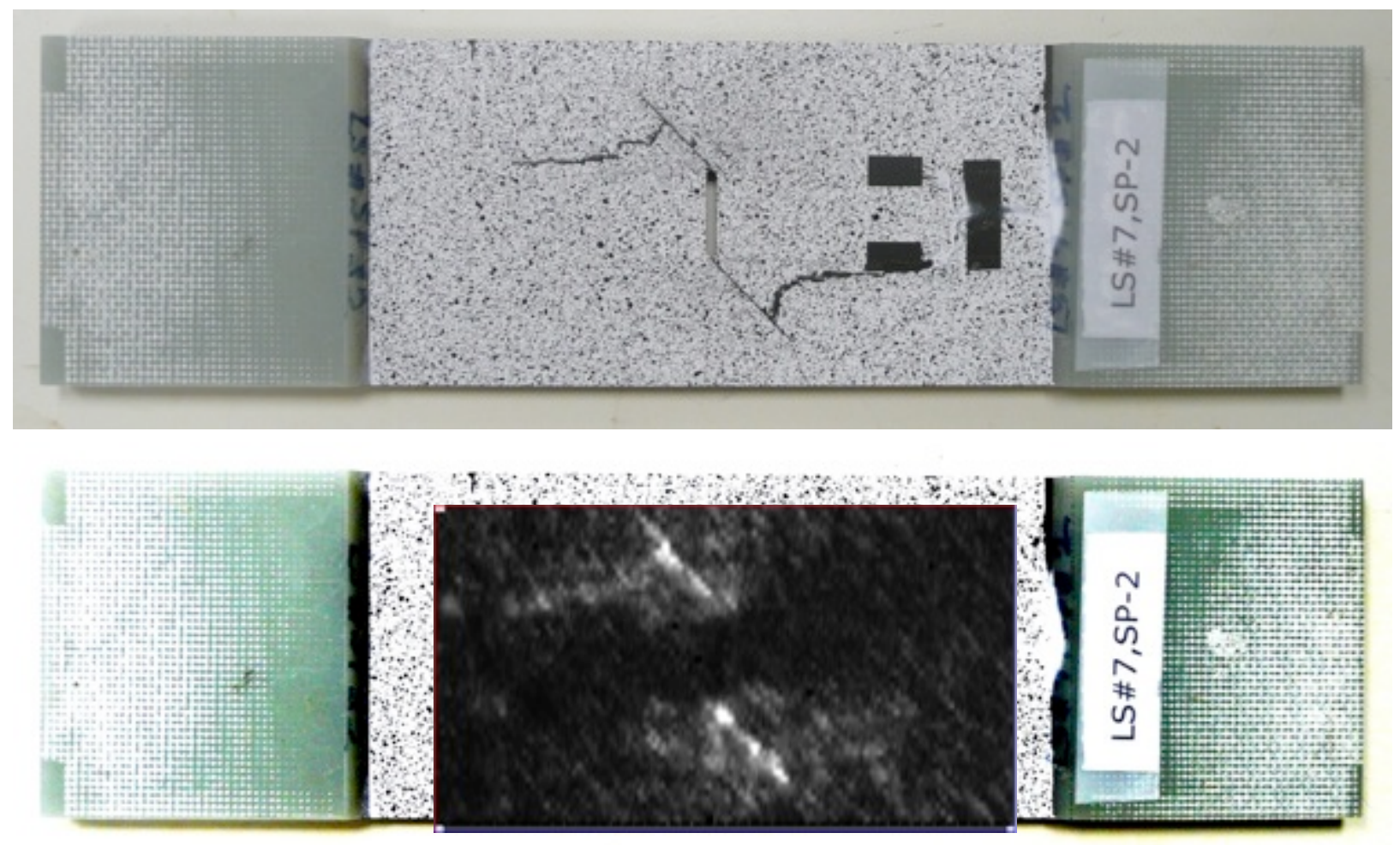

FIGURE 6. Polar backscatter (P-P amplitude) measured by curved array, with fixed polar angle $27^{\circ}$ and azimuthal angle $45^{\circ}$, scanned in X-Y over specimen 1, compared with an optical photograph of the specimen.

suggesting that polar angle may be a sensitive variable in applying polar backscatter. The differences in ultrasonic frequency, bandwidth and beam geometry may also be playing a role.

\section{CONCLUSIONS AND FUTURE WORK}

The work reported in this paper illustrates that polar backscattering measurements provide information about transverse matrix cracks, which normal-incidence backscattering measurements do not. However, while combinations of these measurements can thus provide a more complete description of the damage state in a laminate, scanning a specimen multiple times with a single transducer positioned at various angles of incidence is not always a practical solution. Even scanning a probe having several transducers at fixed angles would not necessarily address the problem adequately.

Modern phased array instruments have demonstrated sufficient scan rates which enables the opportunity to exploit array technology to good advantage in this case. Consider a curved two-dimensional array, as depicted in Fig. 7, where the array elements are spread over a spherically-curved surface, facing the center of curvature. By electronically addressing different sub-apertures in turn, an array instrument could interrogate a point on a specimen, located at the center of curvature, from numerous angles, including normal incidence $(0,0)$. This approach would provide a practical way to acquire the rich amount of information needed to describe many complex damage states.

As stated earlier, the effects of variables such as frequency, bandwidth and beam geometry must also be better understood for effective application of the polar backscattering approach. After further study of these variables, a design can be formulated for a practical 2-dimensional curved polar backscatter array. 
NORMAL INCIDENCE

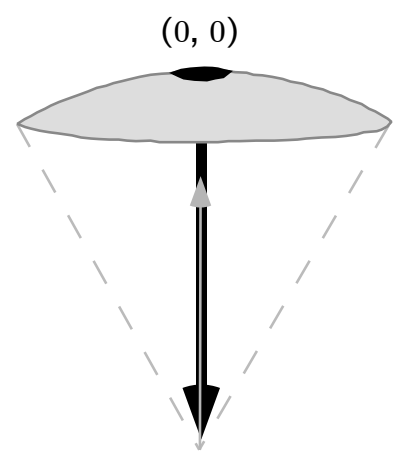

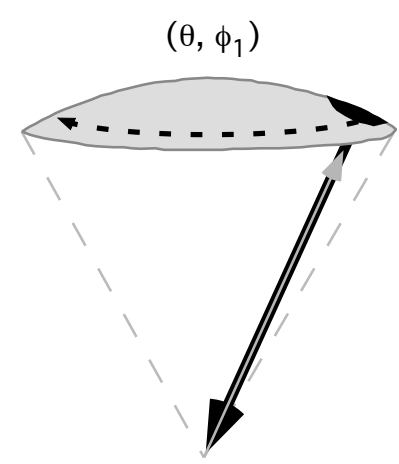

POLAR BACKSCATTER

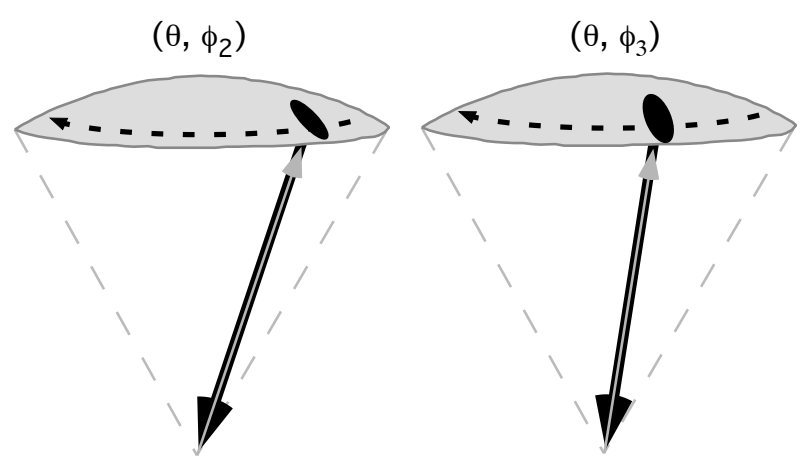

FIGURE 7. Schematic depiction of a proposed 2-dimensional array approach for measuring polar backscatter. Central elements are used for normal-incidence interrogation. Elements at desired polar angle are electronically swept in azimuthal angle, as illustrated by the three azimuthal angles shown, to collect polar backscatter data in near real time.

\section{ACKNOWLEDGEMENTS}

This work was supported by the Vehicle Systems Safety Technologies (VSST) Project and the Subsonic Rotary Wing (SRW) Project. The student authors were supported through the Langley Aerospace Research Student Scholars Program by the Alabama Space Grant Consortium and by the Environmentally Responsible Aviation (ERA) Project.

\section{REFERENCES}

1. E. V. Iarve, M. R. Gurvich, D. H. Mollenhauer, C. A. Rose, and C. G. Dávila, "MeshIndependent Matrix Cracking and Delamination Modeling in Laminated Composites," International Journal for Numerical Methods in Engineering 88, pp. 749773 (2011).

2. P. H. Johnston, C. W. Wright, J. N. Zalameda and J. P. Seebo, "Ultrasonic Monitoring of Ply Crack and Delamination Formation in Composite Tube Under Torsion Load," Proc. 2010 IEEE International Ultrasonics Symposium, pp. 595-598 (2010).

3. J. N. Zalameda, W. P. Winfree, J. P. Seebo and P. H. Johnston, "Thermography Inspection for Detection and Tracking of Composite Cylinder Damage During Load Testing," in Review of Progress in Quantitative Nondestructive Evaluation 30, pp. 450457 (2011).

4. Y. Bar-Cohen and R. Crane, "Acoustic-Backscattering imaging of subcritical flaws in composites," Materials Evaluation 40, pp. 970-975 (1982).

5. B. B. Raju, "Acoustic-backscattering studies of transverse cracks in composite thick laminates," Experimental Mechanics 26, pp. 71-78 (1986).

6. M. Gorman, "Ultrasonic polar backscatter imaging of transverse matrix cracks," Journal of Composite Materials 25, pp. 1499-1514 (1991).

7. A. Satyanarayana, B. P. Bogert and B. P. Chunchu, "The Effect of Delamination on Damage Path and Failure Load Prediction for Notched Composite Laminates", 48th AIAA/ASME/ASCE/AHS/ASC Structures, Structural Dynamics, and Materials Conference, Honolulu, Hawaii, April 23-26, 2007, AIAA 2007-1993. 